\title{
Melon Fly, Bactrocera cucurbitae Coquillett (Insecta: Diptera: Tephritidae) ${ }^{1}$
}

H. V. Weems, Jr., J. B. Heppner, and T. R. Fasulo²

\section{Introduction}

Within its range, the melon fly, Bactrocera cucurbitae Coquillett, is one of the most important pests with which vegetable growers have to contend. Although found in Hawaii, it is not present in the continental United States.

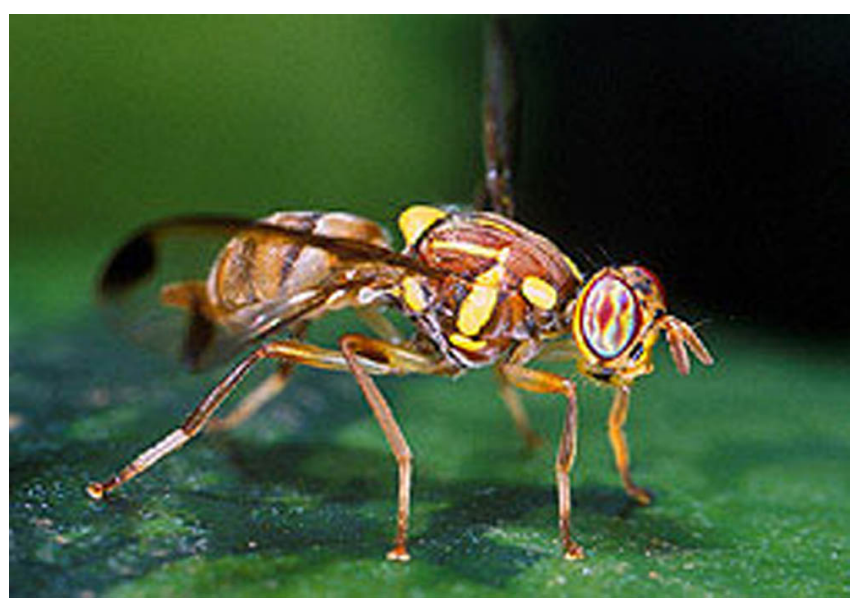

Figure 1. Adult melon fly, Bactrocera cucurbitae Coquillett. Credits: Scott, Bauer, USDA

\section{Synonyms}

Bactrocera cucurbitae Coquillett has also been known as:

Chaetodacus cucurbitae (Coquillett)

Dacus cucurbitae Coquillett

Strumeta cucurbitae (Coquillett)

Zeugodacus cucurbitae (Coquillett)

\section{Distribution}

The melon fly is well distributed over most of India, which is considered its native home, and throughout most of southeastern Asia, the Mariana Islands, and the Hawaiian Islands. It was introduced into the Hawaiian Islands from Japan about 1895, and by 1897 , when it was first observed, it was already a serious pest. Other populations are reported in Africa (Egypt, Kenya and Tanzania), all of southeast Asia as far north as Nepal and China as as far west as Pakistan, the islands in the New Guinea area, Philippines, and Taiwan.

1. This document is EENY-199 (originally published as DPI Entomology Circulars 29 and 315), one of a series of Featured Creatures from the Entomology and Nematology Department, Florida Cooperative Extension Service, Institute of Food and Agricultural Sciences, University of Florida. Published: March 2001. Revised: July, 2004. This document is also available on Featured Creatures Website at http://creatures.ifas.ufl.edu. Please visit the EDIS Website at http://edis.ifas.ufl.edu.

2. H. V. Weems, Jr. and J. B. Heppner, Florida Department of Agriculture and Consumer Services, Division of Plant Industry, and T. R. Fasulo, Entomology and Nematology Department, University of Florida, Gainesville, FL.

The Institute of Food and Agricultural Sciences (IFAS) is an Equal Opportunity Institution authorized to provide research, educational information and other services only to individuals and institutions that function with non-discrimination with respect to race, creed, color, religion, age, disability, sex, sexual orientation, marital status, national origin, political opinions or affiliations. U.S. Department of Agriculture, Cooperative Extension Service, University of Florida, IFAS, Florida A. \& M. University Cooperative Extension Program, and Boards of County Commissioners Cooperating. Larry Arrington, Dean 
It is not established in the continental United States, although a single specimen was collected during July 1956 in Los Angeles County, California, in a glass McPhail trap baited with an aqueous solution of brown sugar, brewers' yeast, and pyridine. Plant quarantine inspectors at west coast ports of entry have made many interceptions in various hosts from Hawaii and occasionally from the Asiatic area. Other interceptions have been made at Houston, Texas; Mobile, Alabama; and Boston, Massachusetts.

\section{Identification}

Adult: The adult fly is 6 to $8 \mathrm{~mm}$ in length. Distinctive characteristics of the adult are the wing pattern, long third antennal segment, the dorsum of the thorax reddish yellow with light yellow markings and without black markings, and the head yellowish with black spots.

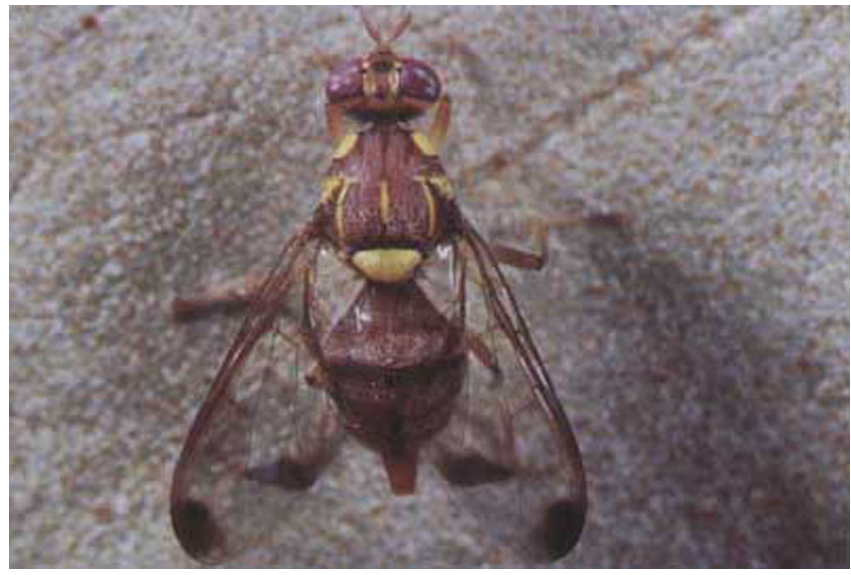

Figure 2. Adult female melon fly, Bactrocera cucurbitae Coquillett. Credits: Jack Clark, University of California

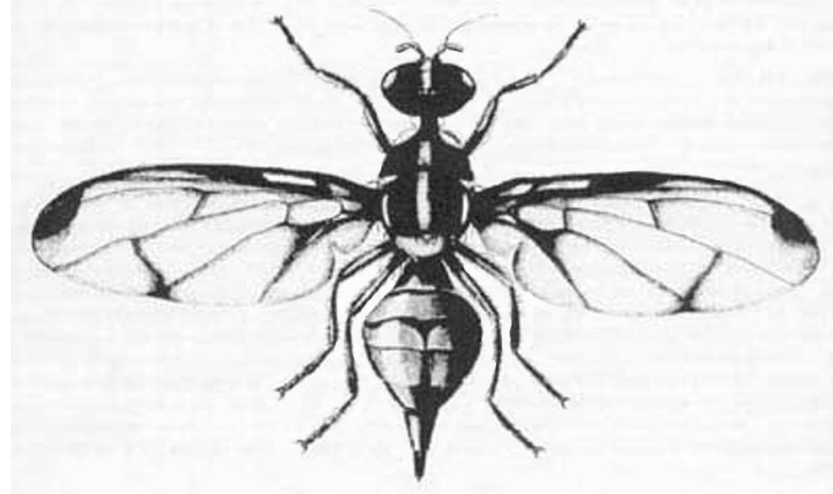

Figure 3. Adult female melon fly, Bactrocera cucurbitae Coquillett, showing wing venation. Credits: Division of Plant Industry
Egg: The egg is pure white, about $2 \mathrm{~mm}$ long, elliptical, nearly flat on the ventral surface, more convex on the dorsal. Eggs often are somewhat curved.

Larva: The larva has three stages. Larva white (except as appearances are altered by the color of the food within the alimentary canal); typical fruit fly shape (cylindrical-maggot shape, elongate, anterior end narrowed an somewhat curved ventrally, with anterior mouth hooks, ventral fusiform areas and flattened caudal end); last instar larvae range from 7.5 to $11.8 \mathrm{~mm}$ in length; venter with fusiform areas on segments 2 through 11 (2 through 4 are weakly developed); anterior buccal carinae usually 18 to 20 in number; anterior spiracles slightly convex in lateral view, with tubules averaging 18 to 20 in number and relatively small.

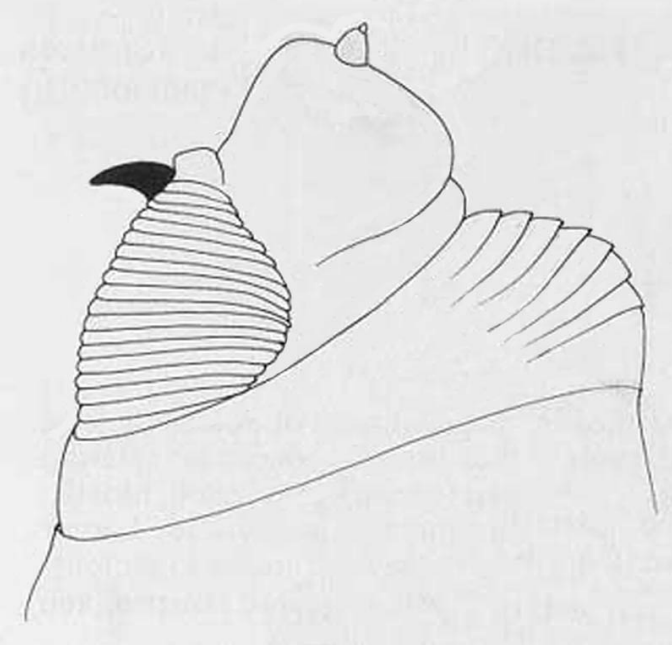

Figure 4. Head and buccal carinae of larva of the melon fly, Bactrocera cucurbitae Coquillett. Credits: Division of Plant Industry

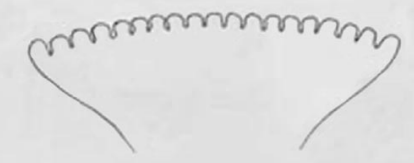

Figure 5. Anterior spiracle.

Cephalo-pharyngeal skeleton with large, sharply pointed convex mouth hook each side, with prominent dorsal lobe, and each hook about $3 \mathrm{X}$ hypostome length; hypostomium with prominent, semi-rounded subhypostomium; post-hypostomial plates curved to dorsal bridge, fused with sclerotized 
rays of central area of dorsal wing plate;

parastomium prominent; dorsal wing plate with posterior ray split; dorsal bridge relatively unsclerotized except on posterior curve to pharyngeal plate; a prominent hood on pharyngeal plate and several striae ventrally.

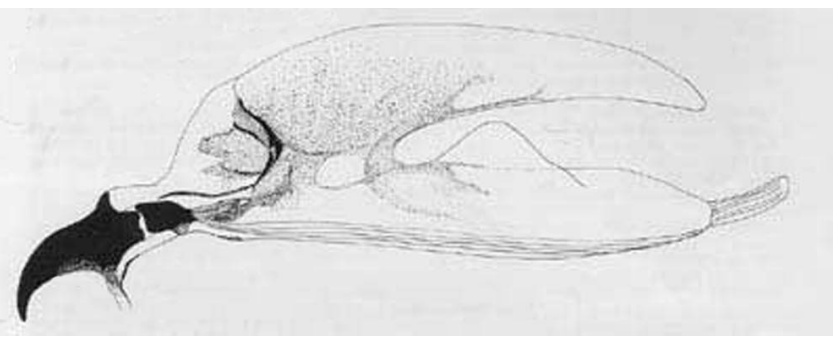

Figure 6. Cephalo-pharyngeal skeleton (left side) of larva of the melon fly, Bactrocera cucurbitae Coquillett. Credits: Division of Plant Industry

Caudal end with paired dorsal papillules (D1 and D2) diagonally dorsad each spiracular plate; intermediate papillules as a curved ridge to each side, with a prominent central dark line below spiracles about midway between spiracles and anal lobes, but with I3 to each side of spiracles; L1 on median edge of caudal end; ventral papillules not evident on raised plates; posterior spiracles as three elongated oval openings (length $=3$ to $3.5 \mathrm{X}$ width) on each kidney-shaped spiracular plate, with dorsal spiracles and lower pair angled to caudal end center; interspiracular processes (hairs) numerous, at 4 sites on each plate, tips bifurcate; anal lobes entire and small.

The larva of the melon fly is particularly distinctive in having a dark sclerotized horizontal line below the spiracular region on the caudal end, with a curved ridge on each side of it. No other known fruit fly larva has this combination of characters, plus other features of the anterior spiracles and cephalo-pharyngeal skeleton (Berg 1979, Chu 1949, Green 1929, Hardy 1949, Phillips 1946, Pruitt 1953).

Pupa: The puparium is about 5 to $6 \mathrm{~mm}$ in length and varies in color from dull red or brownish yellow to dull white, according to host.

\section{Life History}

Development from egg to adult under summer conditions requires from 12 to 28 days, according to the individual and to host and weather conditions.

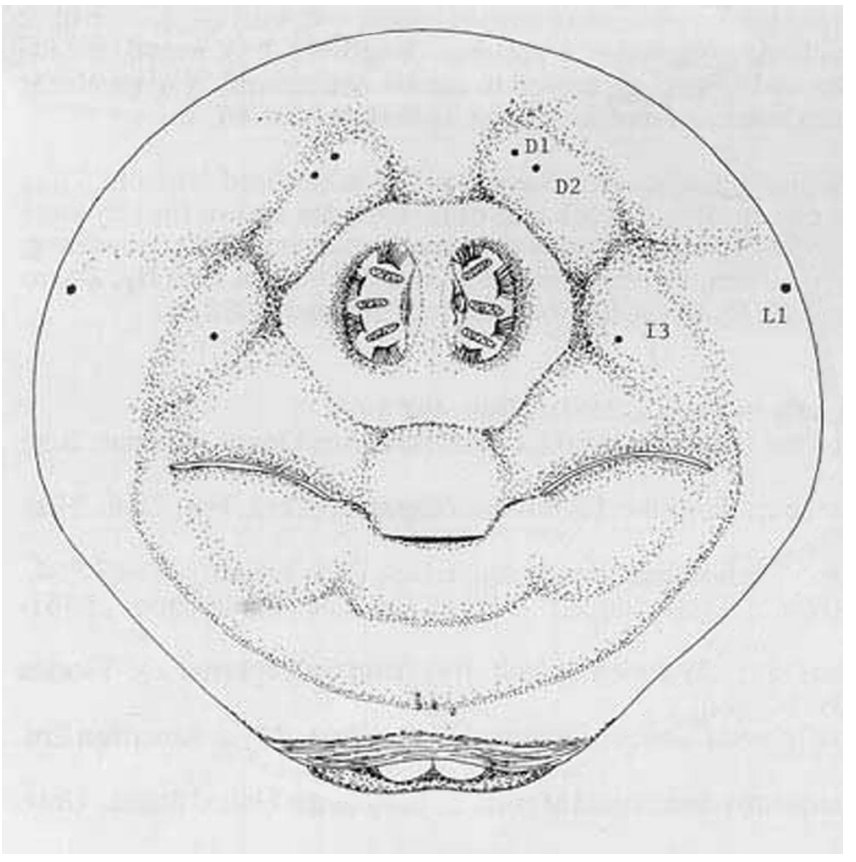

Figure 7. Caudal end of last instar larva of the melon fly, Bactrocera cucurbitae Coquillett. Credits: Division of Plant Industry

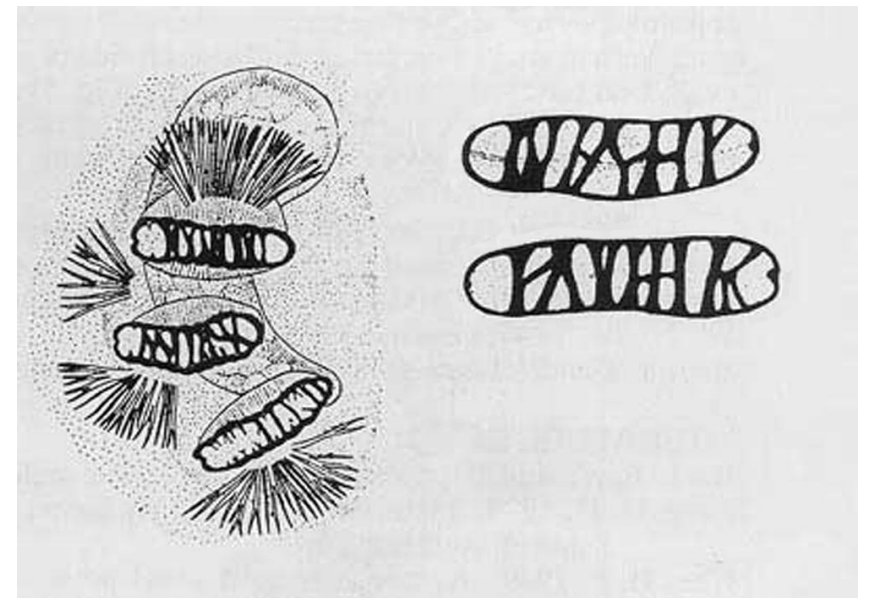

Figure 8. Posterior spiracles (left side) (after Phillips 1946) with detail of two spiracle slits, from the larva of the melon fly, Bactrocera cucurbitae Coquillett. Credits: Division of Plant Industry

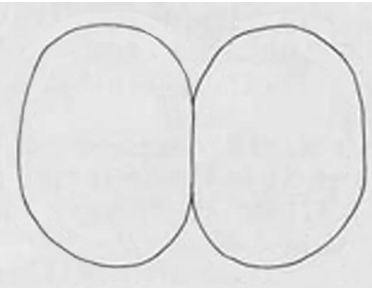

Figure 9. Anal lobes. Credits: Scott, Bauer, USDA

The developmental periods may be extended considerably by cool weather. The length of the stages in the Philippine Islands, at an average 
temperature of $86 \mathrm{~F}$, was 1.73 days for eggs, 4 to 9 days for larvae, and 7 to 11 days for pupae.

Laboratory tests in Hawaii prolonged the egg stage to 11 days, the larval stage to 30 days, and the pupal stage to 51 days, by exposing specimens to low temperatures. In the Philippines the preoviposition period lasted 7 to 26 days and the oviposition period 39 to 95 days. A single hardy female may lay as many as 1,000 eggs. Eggs generally are laid in young fruit, although they are laid also in succulent stems of many host plants, in cavities made with the aid of a sharp ovipositor. Only ripe fruit of some hosts are attacked. Pupation normally occurs in the soil, usually beneath the host, at a depth ranging downward to 2 inches. Adults may live more than a year. Adults feed primarily upon juices of host plants, nectar, and honeydew secreted by various kinds of insects. There may be as many as eight to 10 generations a year.

\section{Damage}

In the Indo-Malayan region, the melon fly, sometimes called the melon fruit fly, is considered the most destructive pest of melons and related crops, and it has greatly curtailed the production of melons, cucumbers, and tomatoes in Hawaii. The extensive damage caused by this fly in areas similar to Florida where it has become established indicates that this species could rapidly become a very serious pest of cucurbits and other truck crops, and possibly of some fruit crops, if it were to be introduced into Florida and be permitted to become established.

In common with some other species in Bactrocera, the melon fly can attack flowers as well as fruit, and additionally will attack stem and root tissue. In Hawaii, pumpkin and squash have been heavily attacked even before the fruit had set, with eggs laid into unopened male and female flowers, and larvae successfully developing in the taproots, stems and leaf stalks.

\section{Hosts}

More than 125 species of plants, including cucurbits, tomatoes, and many other vegetables, have been recorded as hosts of the melon fly. Preferred hosts include cantaloupe, watermelon, pumpkin, squash, gourd, cucumber, tomato, string bean, and cowpea. However, White and Elson-Harris state that many of these records may have been based on casual observations of adults resting on plants or caught in traps set in non-host trees.

Occasional hosts include eggplant, orange, papaya, mango, peach, and fig. Wild hosts include passion-flower, Passiflora spp.; balsam apple; Diplocyclos palmatus; colocynth; Cucumis trigonus; and two genera of cucurbits -- Sicyos sp. and Chinese cucumber, Momordica spp.

\section{Management}

As Bactrocera cucurbitae Coquillett is not found in the continental United States there are no specific management recommendations for its control in Florida. In the Solomon Islands it was subjected to an eradication campaign using a combination of bait spraying and male annihilation traps. In the Ryukyu Islands it was eradicated from some islands using the sterile insect technique. Psyttalia fletcheri (Silvestri) is the only fruit fly parasitoid introduced into Hawaii capable of parasitizing B. cucurbitae.

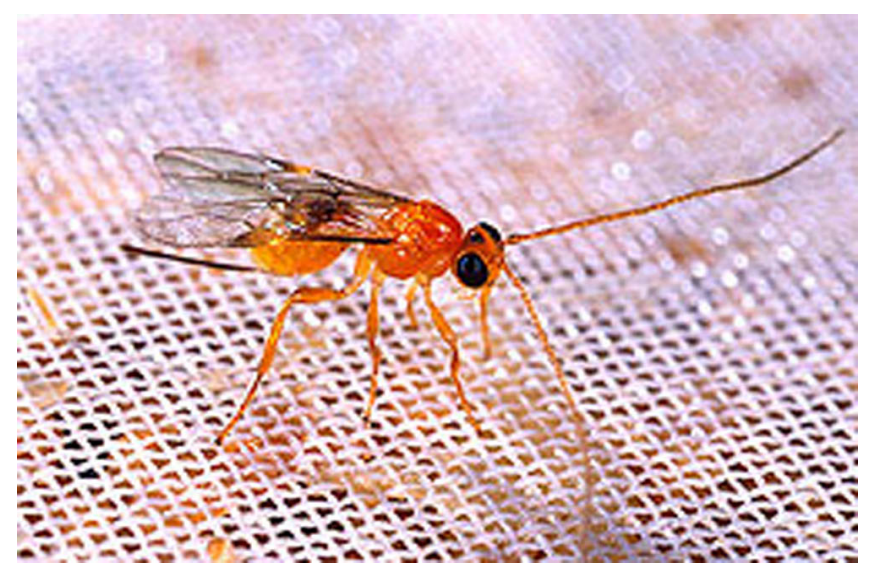

Figure 10. Adult fruit fly parasitoid, Psyttalia fletcheri (Silvestri). Credits: Scott, Bauer, USDA

\section{Selected References}

Anonymous. 1959. Insects not known to occur in the United States. Coop. Econ. Insect Report 9 (19): 343-368. Melon fly (Dacus cucurbitae (Coq.)), 367-368.

Back, E.A., and C.E. Pemberton. 1917. The melon fly in Hawaii. US Department of Agriculture Bulletin 491: 1-64. 
Bautista R, Harris E, Vargas R, Jang E. (2004). Parasitization of melon fly (Diptera: Tephritidae) by Fopius arisanus and Psyttalia fletcheri (Hymenoptera: Braconidae) and the effect of fruit substrates on host preference by parasitoids.

ARS-Research.

http://www.ars.usda.gov/research/publications/ Publications.htm?seq_no_115=155470 (26 July 2004).

Berg, G.H. 1979. Pictorial key to fruit fly larvae of the family Tephritidae. San Salvador: Organ.

Internac. Reg. Sanidad. Agropec. 36 p.

Chu, H.F. 1949. A classification of some larvae and puparia of the Tephritidae (Diptera). Cont. Inst. Zool., Natl. Acad. Peiping (Beijing) 5: 93-138

Green, C.T. 1929. Characters of the larvae and pupae of certain fruit flies. Journal of Agricultural Research (Washington) 38: 489-504.

Hardy, D.E. 1949. Studies in Hawaiian fruit flies (Diptera, Tephritidae). Proceedings of the Entomological Society of Washington 51: 181-205.

Heppner, J.B. 1988. Larvae of fruit flies IV. Dacus dorsalis (Oriental fruit fly) (Diptera: Tephritidae). Florida Department of Agriculture and Consumer Services, Division of Plant Industry Entomology Circular 303: 1-2.

Foote, Richard K., and F.L. Blanc. 1963. The fruit flies or Tephritidae of California. Bulletin of the California Insect Survey 7: 1-117.

Phillips, Venia Tarris. 1946. The biology and identification of trypetid larvae (Diptera: Trypetidae). Memoirs of the American Entomological Society 12: $1-161$.

Pruitt, J.H. 1953. Identification of fruit fly larvae frequently intercepted at ports of entry of the United States. Univ. Florida (Gainesville), MS thesis. 69 p.

USDA, Survey and Detection Operations, Plant Pest Control Division, Agr. Research Service. USDA, Plant Pest Control Division, Agr. Research Service. Anonymous. 1963. The melon fly. Pamphlet $581.4 \mathrm{p}$.
White, I.M., and M.M. Elson-Harris. 1994. Fruit Flies of Economic Significance: Their Identification and Bionomics. CAB International. Oxon, UK. 601 p. 